\title{
National political pressure groups and the stability of international environmental agreements
}

\author{
Achim Hagen ${ }^{1} \cdot$ Juan-Carlos Altamirano-Cabrera ${ }^{2} \cdot$ Hans-Peter Weikard $^{3}$ (D)
}

Accepted: 20 November 2020 / Published online: 3 December 2020

(c) The Author(s) 2020

\begin{abstract}
This paper examines the effects of political pressure groups (lobbies) on transboundary emissions of individual countries and on the stability of international environmental agreements to reduce emissions. We consider two types of lobbies, industry and environmentalists, and we allow for asymmetric countries to consider differences in lobby strengths to study strategic international spillovers of national lobby activities. In our model, lobby groups in countries that are non-signatories to the agreement will impact abatement of the lobby's home country only. In contrast, lobby activities in signatory countries have spillover effects on the abatement decisions of other member countries. As lobby strength impacts abatement, it will, in turn, impact the incentives to participate in the agreement. We find that lobby activities from both lobby groups, industry and environmentalists, can have the potential to facilitate international cooperation to abate global pollution. This, however, depends on the distribution of lobby activities across countries and on whether green lobby groups have a national or international focus.
\end{abstract}

Keywords Interest groups $\cdot$ Coalition theory $\cdot$ Environmental policy making $\cdot$ International environmental agreements $\cdot$ Political economy

JEL Classification C72 $\cdot$ D72 $\cdot$ D78 $\cdot \mathrm{H} 41 \cdot \mathrm{Q} 28 \cdot \mathrm{Q} 54$

\section{Introduction}

Recent events in the international climate policy arena have once more illustrated the fact that national political actors (e.g. lobby groups and voters) are able to affect environmental policy-making, both at the national and the international level. Examples include not only young climate activists pushing their governments to adopt more stringent greenhouse gas abatement measures, as recently described by Marris (2019), but also successful lobbies of

Hans-Peter Weikard

hans-peter.weikard@wur.nl

1 Resource Economics Group, Humboldt-Universität zu Berlin, and Berlin School of Economics, Berlin, Germany

2 Economics Center, World Resources Institute, Washington, DC, USA

3 Section Economics, Wageningen University, Wageningen, The Netherlands 
industries as indicated by the fact that many of the countries with the largest fuel subsidies are among the oil-producing countries (Sovacool 2017; Chepeliev and van der Mensbrugghe 2020). ${ }^{1}$ In light of these observations, it is an important next step to understand the role of lobbies for the formation and stability of international environmental agreements (IEAs). As yet the topic has hardly been addressed in the game theoretic IEA literature with the notable exception of Marchiori et al. (2017).

So far, the literature has convincingly argued that strong free-rider incentives prevent international environmental agreements from being effective (e.g. Hoel 1992; Carraro and Siniscalco 1993; Barrett 1994, 1997; Jeppesen and Andersen 1998). Recent contributions to this literature consider inter alia R\&D efforts (e.g. Nagashima et al. 2011; El-Sayed and Rubio 2014; Silva 2017) and trade (e.g. Nordhaus 2015; Eichner and Pethig 2015; Hagen and Schneider 2017). A common characteristic of these studies is that the participants in international negotiations are treated as monolithic and benevolent governments that truly represent the interests of their constituency. ${ }^{2}$ In particular, it is assumed that governments only care about the aggregate welfare level of their respective country. Thus, in this view, welfare maximisation is the main force that drives environmental policy decisions.

In this paper we consider the stability of IEAs when governments' choices of domestic environmental policies and their decisions at the international negotiation table are impacted by electoral processes and lobby groups. Lobby groups, such as business associations and environmental NGOs, may be able to affect the behaviour of politicians by providing information, by financing election campaigns or by bringing environmental concerns to the forefront of the minds of the voters (Grossman and Helpman 2001). These political factors play an important role when the national representatives meet at the international level and will, in turn, impact the decision whether or not to participate in an IEA.

Most of the studies on the influence of interest groups on policy-making focus on the role of producer groups in the determination of trade policies. In this area, the political contributions approach of Grossman and Helpman $(1994,1995,1996)$ is a standard model which considers self-interested policy-makers who seek to maximise a weighted sum of lobby contributions and the median voter's welfare in order to increase their chances to be reelected. The political contributions approach has been further applied to study environmental policy-making (e.g. Fredriksson 1997; Aidt 1998; Fredriksson et al. 2005; Aidt and Hwang 2014; Batina and Galinato 2017). Fredriksson (1997) shows that there is a relation between the strength of lobby activities and the deviation from an optimal pollution tax. Aidt (1998) explains that lobby groups, through the competitive political process, are important for the internalisation of production externalities. Fredriksson et al. (2005) report empirical evidence for OECD countries that there is an effect of lobby actions on policy-making and that it is more likely to occur in countries with sufficiently high levels of political competition. Aidt and Hwang (2014) study the effects of foreign lobbying as a means of political internalisation of cross-country externalities. Global social welfare would be maximised only under restrictive assumptions, but usually inefficiencies would prevail. Batina and Galinato (2017) describe the trade-offs between the impact of

\footnotetext{
1 The list of examples can easily be extended by pointing to corporations that supported the US climate agenda adopted during Obama's presidency, e.g. Mars, Ikea, Kellogg's and Unilever; these are outnumbered by the efforts of powerful lobbies like the US Chamber of Commerce and the National Association of Manufacturers and the many lobbyists from the coal, oil and natural gas industries (Gunther 2015).

2 Wangler et al. (2013) and Hagen et al. (2017) argue for extending the game theoretical analysis of IEAs to consider actors that are not national governments.
} 
the environmental damage caused by resource extraction and the contributions received from lobbies, when these contributions affect a government's tax and expenditure policies in the presence of tax competition with other governments. Fredriksson et al. (2007) present empirical evidence that the ratification of the Kyoto protocol has been facilitated by environmental lobbying and the effect is stronger in countries with governments that are more susceptible to corruption. Altamirano-Cabrera et al. (2007) have studied the impact of lobby groups on the stability of climate agreements in an empirically calibrated simulation model. They find that although lobby contributions may help to stabilise IEAs, the additional greenhouse gas abatement is marginal. Anger et al. (2015) assess the effect of lobby actions on emission allowance allocations under the EU emissions trading scheme (ETS). They find that lobbying of energy-intensive firms within the ETS shifts the regulatory burden of emission abatement to non-ETS sectors. As a result, marginal abatement costs differ between ETS and non-ETS sectors, which is generally inefficient.

There are few examples of theoretical studies that combine an analysis of the influence of interest groups (e.g. using the political contributions approach) with an analysis of international cooperation. Such a combined approach is adopted, for instance, by Kim (2013) and Habla and Winkler (2013). Kim (2013) analyses using a two-country model with a clean and a dirty good, the conditions under which a politically viable IEA could evolve; the price elasticities of supply and the weights politicians place on general welfare versus lobby contributions turn out to be key factors. Habla and Winkler (2013) examine an international emission permit market where lobbies can impact both domestic emissions and participation in the market. While such two-country models highlight sometimes counter-intuitive impacts of strategic policy interaction on the domestic and international level, they cannot address the question of free-riding and IEA stability as a coaliton formation problem. Closest to our paper is work by Haffoudhi (2005) and Marchiori et al. (2017), who have studied the impact of lobby groups on the size and stability of IEAs for multiple homogeneous countries. Haffoudhi (2005) finds that a global agreement could be sustained by means of industry lobby contributions. Similarly, Marchiori et al. (2017) find that a strong industry lobby may increase the incentives of the government to participate in an agreement. This result is driven by the assumption that the government can commit to a stricter abatement policy by joining the IEA before lobby groups can announce prospective contributions. A government of a member country can thus collect larger lobby contributions from industry than an outsider country could collect for the same emission policy. In addition they show that, in a different game where lobby contributions are contingent on the membership decision, industry contributions decrease the size of an IEA.

To zoom in on the analysis of impacts of lobbying, we analyse a model where lobby strengths can differ across countries, but countries are equal in all other aspects, such as benefits and costs of emission abatement. As in Grossman and Helpman (1994), we assume that lobbies try to influence the government's policy decisions, and we abstract from the election process. We represent lobbies' influence as prospective contributions that enter into the government's political revenue function and are made conditional on a change of government's policy decisions.

The formation of IEAs is modelled as a game in which governments decide about their participation before they choose their abatement strategies-considering both net welfare benefits from abatement and the prospective lobby contributions. For the analysis of IEA stability, we employ the concept of internal and external stability introduced by d'Aspremont et al. (1983). We assume that there are two lobbies from which governments can obtain contributions: industry and environmentalists. We consider that the level of contributions depends on each lobby's payoff function and the abatement strategy chosen by 
the government. The payoff of an environmentalist lobby depends on the additional abatement efforts undertaken and the contribution it commits to pay. We assume that the industry lobby is always harmed if the government policy increases abatement. Relaxing the symmetry assumption invoked by Haffoudhi (2005) and Marchiori et al. (2017), we are able to study international spillover effects that cannot occur in a model with symmetric players. Our results show that the influence of lobby groups has an effect on the abatement decisions of the respective countries. This influence can be observed for members of an IEA, as well as for outsiders. In the case of IEA members, the effects of lobbying are not restricted to the lobby's host country, but spill over to other member countries and have ambiguous effects on the IEA stability. In case of symmetric lobbying in all countries, we confirm the results from Marchiori et al. (2017) and find that industry contributions have a stabilising effect on IEAs. However, this result changes if countries are heterogeneous in lobby strength. Depending on the composition of the IEA and on whether green lobby groups have a national or international focus, both industry and environmentalists can have a stabilising effect. In line with results by Finus and McGinty (2019), we find possibly large stable IEAs when lobby strength is sufficiently different between IEA members.

The remainder of the paper is structured as follows. First, we lay out our model and explain the stages of the game. We then solve the game by backward induction and focus on the abatement decisions of the countries (Sect. 3) and the stability of the IEA (Sect. 4). In Sect. 5 we look at a generalisation of our model to compare green lobbies with different degrees of international orientation. We conclude the paper with a summary and discussion.

\section{Description of the model}

We study the impact of lobbying on the formation and stability of IEAs in a sequential game. The players in our game are lobbies and governments in $n$ countries. The set of countries is denoted $N$. An IEA is a subset of all countries $S \subseteq N$. Our game starts with (1) the announcements of the lobby contributions. This is followed by the workhorse model of IEA formation with two stages, (2) governments' participation decision and (3) the transboundary pollution game. Finally, (4) lobby contributions are paid according to the announcements at stage 1 . We describe these stages in more detail in turn.

\subsection{Announcement of the lobby contributions and formation of an IEA}

Lobbying takes place in all countries $i \in N$ and affects national policies. In our model, the policy space is the level of abatement, reflecting the strictness of the environmental policy adopted. Hence, a particular policy is described by a country's abatement $q_{i} \in[0, \bar{e}]$, where index $i$ refers to an individual country and $\bar{e}$ is the level of business-as-usual emissions level assumed to be identical across countries. We denote the policy of a signatory country $i \in S$ by $q_{i}^{s}$ and the policy of a non-signatory $i \in N \backslash S$, an outsider, by $q_{i}^{\text {out }}$. Following a common assumption in the literature (c.f. Grossman and Helpman 1996; Aidt 1998; Conconi 2003), we assume two exogenously given lobby groups, (i) the industry, referred to as "firms" $f$, and (ii) the environmentalists, referred to as "greens" $g$. The firms' preferred policy is $q_{i}=0$, i.e. their preferred level of abatement is zero as this avoids abatement costs. By contrast, the greens' preferred policy is full abatement. Hence both lobbies pull in opposite directions. The government maximises a political revenue function that reflects 
social welfare and the influence of lobby groups. We model lobby pressure as prospective contributions that reflect the willingness to pay of a lobby to influence the government's policy decisions in their favour.

Contributions represent the monetary value assigned to all lobbying activities that influence a government's decisions. ${ }^{3}$ The political revenue function thus has two components. First, it is a function of a country's net benefits from the environmental policy adopted. This may include the net benefits resulting from participating in an IEA. Second, political revenue depends on the contributions from lobby groups. The political revenue function of the government in country $i, \pi_{i}$, reflects the benefits and costs of greenhouse gas abatement and the prospective contributions, $L$, from lobby groups supporting the government's policy. The political revenue function is

$$
\pi_{i}\left(q_{i}, q\right)=B(q)-C\left(q_{i}\right)+\lambda_{i} L_{i}\left(q_{i}, q\right)
$$

where $B(q)$ are the total benefits from global abatement denoted by $q=\sum_{i \in N} q_{i}$, and $C\left(q_{i}\right)$ are the abatement costs from own abatement $q_{i}$. We assume that $B(q)$ is increasing and weakly concave, i.e. $\frac{\partial B}{\partial q}>0$ and $\frac{\partial^{2} B}{\partial q^{2}} \leq 0$, while $C\left(q_{i}\right)$ is increasing and strictly convex, i.e. $\frac{\partial C}{\partial q_{i}}>0$ and $\frac{\partial^{2} C}{\partial q_{i}^{2}}>0$. The parameter $\lambda_{i}$ captures the relative weight a government attaches to contributions compared to net benefits from abatement; it measures a government's susceptibility to lobby contributions. Finally, $L_{i}\left(q_{i}, q\right) \geq 0$ represents the total contributions from local lobbies which are the sum of firms' and greens' contributions, $L_{i}\left(q_{i}, q\right) \equiv L_{i}^{f}\left(q_{i}\right)+L_{i}^{g}(q)$, with firms' contributions $\frac{\partial L_{i}^{f}}{\partial q_{i}}<0$ and $\frac{\partial^{2} L_{i}^{f}}{\partial q_{i}^{2}} \leq 0$ and greens' contributions $\frac{\partial L_{i}^{g}}{\partial q}>0$ and $\frac{\partial^{2} L_{i}^{g}}{\partial q^{2}} \leq 0$. Lobby contributions will be further specified below. ${ }^{4}$

In the first stage, lobby groups announce their prospective contributions to their countries' governments which are contingent on the governments' abatement decisions. At stage 2, all countries $i \in N$ decide simultaneously whether or not to join an IEA. We denote country $i$ 's choice to join and become a signatory by $\sigma_{i}=1$. If country $i$ does not join, $\sigma_{i}=0$, it remains a singleton player. The signatories $S \subseteq N$ act jointly at stage 3 , i.e. they act like a single player in the global pollution game. If no country or only a single country joins the IEA, then there is no effective agreement. We refer to this situation as "All Singletons" and denote it by $S=\emptyset$. If $S=N$, we have the Grand Coalition. We assume that signatories make a binding agreement. Hence, we restrict our attention to participation and do not discuss enforcement. ${ }^{5}$

\subsection{The global pollution game and payment of lobby contributions}

As the focus and the novelty of this paper is the analysis of the impact of lobbying on international environmental policy making, we employ, for ease of comparison, a global pollution game that is standard in the literature and has been used frequently (e.g. Barrett 1994; Asheim and Holtsmark 2009; Alvarado-Quesada and Weikard 2017). We consider a

\footnotetext{
3 Some authors argue that contributions may be interpreted as bribes in order to influence government policies (see Schulze and Ursprung 2001).

${ }^{4}$ Contribution functions are assumed to be concave in abatement because it is natural to assume that marginal benefits, and hence marginal contributions of the greens, are decreasing; and marginal costs are increasing implying decreasing marginal contributions of the firms.

5 McEvoy and Stranlund (2009) and Yu et al. (2017) introduce models that address both issues.
} 
uniformly mixing pollutant (such as greenhouse gases). In this setting, abatement is a pure public good. At the abatement stage, the IEA has been formed and, as indicated before, we assume that it behaves like a single player. Hence, the players of the global pollution game are the IEA members and the remaining singletons. Each non-signatory government chooses abatement to maximise its political revenue given by (1). To arrive at closed-form solutions, we assume that benefits are linear and costs are quadratic in abatement. Since we focus our study on the effects of lobby groups on governments' abatement and participation decisions, we assume that countries are symmetric in their direct costs and benefits of abatement, but governments attach different relative weights to contributions, and lobbies may differ in strength. Thus we have $B(q)=b q$ and $C\left(q_{i}\right)=\frac{1}{2} c q_{i}^{2}$ with parameters $b, c>0$.

In our game, firms gain from lower abatement as they save costs; environmentalists gain from higher (global) abatement as pollution damages are reduced. Thus the lobby contributions can be described as follows. Firms in country $i$ face additional abatement costs. They bear a fraction $\phi_{i}$ of these costs, while a fraction $1-\phi_{i}$ is passed on to consumers. Hence, we stipulate that firms' willingness to pay for reducing abatement is given by $L_{i}^{f}\left(q_{i}\right)=\hat{L}_{i}^{f}-\phi_{i} \frac{1}{2} c q_{i}^{2}$, where $\hat{L}^{f}$ denotes the contribution that firms are willing to make if their preferred policy $q_{i}=0$ is adopted. ${ }^{6}$ The greens appreciate any avoided damage from emissions, i.e. the benefits of abatement. Their willingness to pay for additional abatement is $L_{i}^{g}(q)=\gamma_{i} q$, where $\gamma_{i}>0$ is a scaling parameter that captures the greens' preference for money vis-à-vis the avoided damage. In contrast to the firms, the greens offer contributions that depend on global abatement as they are concerned with damages from pollution. In Sect. 5 we will relax this assumption and consider the case of a green lobby that only rewards their own government's abatement efforts. We consider only positive lobby contributions (c.f. Habla and Winkler 2013) so that lobbies are not compensated for potential losses from the government's decisions. We interpret parameters $\phi$ and $\gamma$ as lobby strength. Thus we have

$$
\pi_{i}\left(q_{i}, q\right)=b q-\frac{1}{2} c q_{i}^{2}+\lambda_{i}\left(\hat{L}_{i}^{f}-\phi_{i} \frac{1}{2} c q_{i}^{2}+\gamma_{i} q\right) .
$$

With $\lambda_{i} \geq 0$. Equation (2) implies that the political revenue function shows linear political benefits and quadratic political costs. This specification allows us to draw on established results (e.g. Finus and McGinty 2019) but with a quite different interpretation.

Signatory governments cooperatively decide about their abatement to maximise the joint payoffs $\sum_{i \in S} \pi_{i}$ which include lobby contributions. The abatement decisions are modelled as a simultaneous-move game. After the governments have decided about their emission abatement, payoffs are determined on the basis of abatement costs and benefits, and lobby groups pay contributions according to their announcements. Given our specifications, the abatement game has a unique Nash equilibrium.

\footnotetext{
${ }^{6}$ Other assumptions for the firms are also possible and do not change the results as long as both lobby groups choose to pay lobby contributions and we have an interior solution. Since we observe both environmentalists' and firms' lobbying activities in the international policy arena, this seems to be a reasonable assumption.
} 


\section{Equilibrium emission abatement}

The game is solved by backward induction. We start the analysis at the last stage of the game. At this stage, lobbies pay their contributions depending on the abatement decisions of the countries. Lobbies are committed to the contribution schedules announced in the first stage of the game. Here the analysis can draw on results by Bernheim and Whinston (1986) who have shown that lobby groups do not lose by announcing truthful contribution schedules. A truthful contribution schedule is one that reflects a lobby's willingness to pay for a policy change in their favour. Hence we can assume that both lobbies' equilibrium offers are as specified in the previous section.

In the third stage of the game, emission abatements are chosen. All non-signatories maximise their political revenue functions simultaneously with the signatories' joint decision. Maximisation of (2) yields the non-signatories' abatement decision dependent on the lobby contributions proposed in the first stage:

$$
q_{i}^{\text {out }}=\frac{b+\lambda_{i} \gamma_{i}}{c\left(1+\lambda_{i} \phi_{i}\right)} .
$$

We see that non-signatories have dominant abatement strategies that do neither depend on the number of IEA signatories nor on the abatement of others.

The signatories of the IEA coordinate their environmental policies to maximise the joint political revenues of the governments involved $\pi^{S}\left(q_{i}^{s}, q\right)$, i.e.

$$
\pi^{S}\left(q_{i}^{s}, q\right)=\sum_{i \in S} \pi_{i}\left(q_{i}^{s}, q\right)=\sum_{i \in S}\left[b q-\frac{1}{2} c\left(q_{i}^{s}\right)^{2}+\lambda_{i}\left(\hat{L}_{i}^{f}-\phi_{i} \frac{1}{2} c q_{i}^{2}+\gamma_{i} q\right)\right] .
$$

The solution of this maximisation problem yields the abatement decision for each member country $i \in S$ dependent on the lobby contributions

$$
q_{i}^{s}=\frac{\sum_{j \in S}\left(b+\lambda_{j} \gamma_{j}\right)}{c\left(1+\lambda_{i} \phi_{i}\right)} .
$$

Comparing (3) and (5) we directly see that signatories abate a larger amount of their emissions than the non-signatories, assuming the strength of lobby contributions is the same across countries.

Proposition 1 The inclusion of lobby groups has an effect on the best response abatement quantities of signatories and non-signatories. (1) The inclusion of firms' lobby contributions in any country $i \in N$ results in lower abatement in that country. (2) The inclusion of green lobbies in any country $i \in N$ results in higher abatement in that country. (3) Green lobbying in signatory countries $i \in S$ has a spillover effect on abatement decisions in all other signatory countries, i.e. other signatories abate more as a response to green lobby contributions in some member country $i \in S$.

Proof All proofs are given in "Appendix".

Already at this stage we see from part (1) of Proposition 1 that lobby groups influence global emission abatement in the "All Singletons" situation with $S=\emptyset$ and in the case of partial coalitions $S \subseteq N$. While the presence of greens leads to a larger amount of globally abated emissions, firms' lobbying reduces global mitigation efforts. From part (3) of Proposition 1, 
we see an effect of green lobbying on the abatement of not only the lobby's host country but also other members. We refer to this as the leverage effect of green lobbying in member countries. The effect stems from the greens' concern for global abatement and coalition members' commitment to account for abatement impacts on fellow members, so that externalities are internalised within the coalition.

\section{IEA formation}

To solve the participation stage of the game, we apply the concept of potential internal stability (Carraro et al. 2006; Weikard 2009) which employs the idea that transfers between coalition members can guarantee internal stability if and only if the coalition payoff (weakly) exceeds the sum of outside option payoffs. The outside option payoff is the payoff that accrues to a member when it leaves the coalition, while the others maintain membership (as we only consider single deviations). Potential internal stability is a refinement of the concepts of internal and external stability that are widely used in IEA analysis. These concepts, initially borrowed from cartel theory (d'Aspremont et al. 1983), define a stable coalition as one in which no member is better off by leaving the coalition and no non-member gains by joining the coalition. The abatement subgame starting at stage 3 has a unique equilibrium. This fact can be used to define a partition function which expresses each government's payoff as a function of the coalition that has been formed at the previous stage. For any given coalition $S$, Eqs. (3) and (5) give the equilibrium abatement quantities. For a given coalition $S$, let $q^{*}(S)$ denote the sum of equilibrium abatement quantities. We can write the partition function as

$$
V_{i}(S) \equiv \begin{cases}\pi_{i}^{S}\left(q_{i}^{S}, q^{*}(S)\right) & \text { if } i \in S, \\ \pi_{i}^{\text {out }}\left(q_{i}^{\text {out }}, q^{*}(S)\right) & \text { if } i \in N \backslash S .\end{cases}
$$

In a setting with symmetric countries, an analysis of IEA stability is usually based on a stability function that describes the incentives of a country to be a member of a coalition as a function of the size of the coalition. In our setting with asymmetric countries, incentives of a country to be in coalition $S$ may depend on the characteristics of the members of $S$. A country's incentive $\Phi_{i}$ to participate in $S$ is defined as $\Phi_{i} \equiv V_{i}(S)-V_{i}\left(S_{-i}\right)$. Potential internal stability is defined as follows.

Definition 1 Coalition $S \subseteq N$ is potentially internally stable if and only if $\sum_{i \in S} \Phi_{i} \geq 0$.

The definition states that potential internal stability of a coalition is guaranteed if the coalition payoff is larger than the sum of the outside option payoffs of the members. Clearly potential internal stability is a necessary but not a sufficient condition for coalition stability.

Given the specifications we have adopted, and using notation $q^{*}(S)$ for the equilibrium abatement at stage 3 , we can write the condition of potential internal stability as follows.

$$
\begin{aligned}
0 \leq & \Phi(S) \equiv \sum_{i \in S} \Phi_{i}=\sum_{i \in S} b q^{*}(S)-\sum_{i \in S} \frac{1}{2} c\left(q_{i}^{*}(S)\right)^{2}+\sum_{i \in S} \lambda_{i}\left[L_{i}^{f}\left(q_{i}^{*}(S)\right)+L_{i}^{g}\left(q^{*}(S)\right)\right] \\
& -\sum_{i \in S} b q^{*}\left(S_{-i}\right)+\sum_{i \in S} \frac{1}{2} c\left(q_{i}^{\text {out }}\right)^{2}-\sum_{i \in S} \lambda_{i}\left[L_{i}^{f}\left(q_{i}^{\text {out }}\right)+L_{i}^{g}\left(q^{*}\left(S_{-i}\right)\right)\right] .
\end{aligned}
$$


In the absence of lobbying, as countries are symmetric by assumption, we obtain from Eq. (6)

$$
\Phi(S)=\sum_{i \in S} b\left[q^{*}(S)-q^{*}\left(S_{-i}\right)\right]-\sum_{i \in S} \frac{1}{2} c\left[\left(q_{i}^{*}(S)\right)^{2}-\left(q_{i}^{\text {out }}\right)^{2}\right] .
$$

By substituting $q_{i}^{*}(S)=\frac{\sum_{j \in S} b}{c}$ and $q_{i}^{\text {out }}=\frac{b}{c}$ into (7) we obtain the well-known result that a coalition of three countries is internally stable (c.f. e.g. Barrett 1994).

We can now turn to the effects of lobbying activities on the stability of IEAs through further inspection of (6). We can show the following.

Proposition 2 Lobbying activities in singleton countries have no effect on potential internal stability of a coalition.

Both green and firm lobbying activities in non-signatory countries have no effect on the potential internal coalition stability. While lobbying in these countries changes their emission abatement and in turn also the benefits of coalition members, the incentives to leave the coalition are unaffected by non-signatories' lobbying, because the change of benefits through spillovers affects the coalition payoff and the outside option payoff in the same way. Lobby activities in singleton countries may, however, affect external stability. For example, a singleton country with a strong green lobby behaves as if it had high benefits. Thus a green lobby can change that country's incentives to join a coalition. Hence, through lobbying in singleton countries, a coalition may "grow" but would not "decline". One way to check external stability of a coalition $S$ is to show that there is no $j \notin S$ such that the enlarged coalition $S \cup\{j\}$ is potentially internally stable [see Weikard (2009, Lemma 1)]. Hence we need to examine whether lobby contributions of a member can stabilise an otherwise internally unstable coalition. For green lobby contributions we find the following.

Proposition 3 (i) Contributions of a green lobby in a signatory country with (sufficiently) high political revenues from abatement have a positive effect on coalition stability and (ii) can stabilise an otherwise unstable coalition. (iii) Contributions of a green lobby in a signatory country with (sufficiently) low political revenues from abatement have a negative effect on coalition stability.

To understand the intuition for Proposition 3, it is helpful to think about the different types of gains from cooperation that occur when a country joins the coalition in relation to its freerider payoff. On the one hand, welfare gains are achieved by internalising the positive externalities among the members. However, these gains also benefit free-riding countries. Finus and McGinty (2019) argue that a second type of gains from joining a coalition exists which are important for the stability of the coalition: the gains from cost-effective cooperation which are exclusive to the members and thus increase the gains from cooperation relative to the gains from free riding. ${ }^{7}$ Finus and McGinty (2019) show that those gains increase with the degree of asymmetry of benefit shares. This is because large asymmetries of marginal benefits would result in abatement choices characterised by large differences of marginal costs between countries in the absence of cooperation. This implies an inefficiency that is removed when countries form a coalition. In our case, we see that green lobby contributions increase coalition

$\overline{7}$ Note that these gains hinge on the existence of transfers as discussed by Weikard and Dellink (2014). 
stability if the green lobby is strong, and contributions have a large weight in the political revenue function of a country. This results from an increase of the asymmetry of marginal political revenues which, in turn, increases cooperative gains in political revenues that are exclusive to the coalition. Conversely, additional green lobby contributions in a member country with low green lobby contributions compared to other countries decrease the asymmetry of political revenues from abatement and thus have a negative effect on the political revenue gains from cooperation and coalition stability. We will return to this result in the next section where we disaggregate green contributions that are motivated by either national or international abatements.

In the proof of part 2 of Proposition 3 we show how the lobby contribution needed to stabilise a given coalition can be determined. Note that gains in terms of political revenues resulting from coalition formation will not necessarily be welfare gains. Green lobbying can be effective in terms of boosting abatement, but it will not be cost-effective in welfare terms. Still, coalitions stabilised by a green lobby might increase global welfare because cooperation increases abatement reducing its underprovision that stems from free-rider incentives.

Turning to firms' lobbying we find the following.

Proposition 4 The effects of firms' lobby activities in a signatory country on coalition stability are (i) independent of contributions of firms in other countries but (ii) depend on the distribution of green lobby activities across other member countries. Firms' lobby activities will have a positive effect on coalition stability if political revenues from abatement are evenly distributed. If political revenues of other member countries are sufficiently dispersed, firms' lobbying activities will have a negative impact on coalition stability.

To understand this result, first, consider that green lobby contributions are similar in member countries (weak asymmetry of political revenues between member countries). In this case firms' contributions in a country will effectively make abatement more expensive for the government (in political revenue terms). Hence, such contributions create a cost asymmetry and increase the gains from cost-effective cooperation that is exclusive to members; therefore, coalition stability increases. This could generate larger coalitions, but with more modest abatement targets of the members since firms' contributions drive political revenues.

Second, stronger asymmetries of benefits between members, due to green lobbies, may help to stabilise large coalitions. We see in this case that firms' lobby contributions counteract this stabilisation (cf. Finus and McGinty 2019). Firms' lobby contributions can then effectively reduce the size of the IEA and, in turn, lower the abatement of both the remaining members and of countries leaving the coalition.

\section{International orientation of green lobbies}

In this section we relax the assumption that green lobbies are interested in global abatement and we explicitly consider green lobbies that focus on national climate policy. The following specification allows for a comparison of green lobbies with different degrees of international orientation: ${ }^{8}$

${ }^{8}$ We thank one of our reviewers for suggesting this model extension. 


$$
\pi_{i}\left(q_{i}, q\right)=b q-\frac{1}{2} c q_{i}^{2}+\lambda_{i}\left(\hat{L}_{i}^{f}-\phi_{i} \frac{1}{2} c q_{i}^{2}+\gamma_{i}^{D} q_{i}+\gamma_{i}^{I} q_{-i}\right)
$$

where $q_{-i}=\sum_{j \in N_{-i}} q_{j}, \gamma_{i}^{D} \geq 0$ is the green contribution motivated by domestic abatement and $\gamma_{i}^{I} \geq 0$ is the green contribution motivated by international abatement.

This specification contains as special cases the option that green lobbies only care for national abatement when $\gamma_{i}^{I}=0<\gamma_{i}^{D}$ and that green lobbies only care for global abatement, as in the previous sections, when $\gamma_{i}^{D}=\gamma_{i}^{I}>0 .{ }^{9}$ In this case, the equilibrium abatement quantities for non-signatories in the second stage are determined from maximisation of (8)

$$
q_{i}^{\text {out }}=\frac{b+\lambda_{i} \gamma_{i}^{D}}{c\left(1+\lambda_{i} \phi_{i}\right)}
$$

whereas signatories maximise the joint political revenues of all involved governments:

$$
\pi^{S}\left(q_{i}^{s}, q\right)=\sum_{i \in S} \pi_{i}\left(q_{i}^{s}, q\right)=\sum_{i \in S}\left[b q-\frac{1}{2} c q_{i}^{2}+\lambda_{i}\left(\hat{L}_{i}^{f}-\phi_{i} \frac{1}{2} c q_{i}^{2}+\gamma_{i}^{D} q_{i}+\gamma_{i}^{I} q_{-i}\right)\right] .
$$

The solution yields the abatement decision for each member country $i \in S$ dependent on the lobby contributions

$$
q_{i}^{s}=\frac{b+\lambda_{i} \gamma_{i}^{D}+\sum_{j \in S \backslash i}\left(b+\lambda_{j} \gamma_{j}^{I}\right)}{c\left(1+\lambda_{i} \phi_{i}\right)} .
$$

From (9) and (11) the following qualification of Proposition 1 results.

Proposition 5 For any country $i \in N$, green lobbies with an interest in national abatement stimulate higher abatement in their host country. Internationally focused green lobby activities do not affect equilibrium abatement of their host country; however for signatory countries $i \in S$, all other signatories $j \in S \backslash i$ abate more as a response to green lobby contributions in country $i$.

With these results we can turn to the effects of nationally and internationally oriented green lobby contributions on coalition stability. Using again the concept of potential internal stability we get the following result.

Proposition 6 (i) Contributions of a green lobby group with national interests in a signatory country decrease coalition stability. (ii) Contributions of an internationally oriented green lobby group in signatory countries increase coalition stability.

To understand why an increase in green lobby strength with a national focus in a member country decreases coalition stability the following intuition is helpful. A stronger nationally focused green lobby increases a country's abatement, no matter if it is a member

\footnotetext{
${ }^{9}$ Hillman and Ursprung (1994) distinguish these two types of environmental lobbies which they label "greens" and "supergreens". These are driven by local or global concerns, respectively. Using this terminology our model in Sect. 2 describes supergreens; the model in this section allows for any environmental lobby between greens and supergreens.
} 
or an outsider of a coalition. This increases all countries' benefits independently of the coalition structure. However, the costs from the increased abatement are higher for a member country that has higher total abatement than for an outsider country because abatement costs are convex. This makes a coalition with the respective country less attractive compared to the case where this country is an outsider. On the other hand, if the influence of internationally oriented green lobbies in a country increases, this increases both benefits and contributions of other member countries in case that the respective country is a member, but does not change its own contributions. In contrast, for an outsider country nothing changes because the contributions do not incentivise abatements. The increased green influence thus makes membership comparatively more attractive for the respective country and therefore increases coalition stability.

This result also sheds more light on the findings presented in Proposition 3 in the previous section. The ambiguous effects we find for green lobby contributions motivated by global abatement can now be understood as the aggregate of two effects, namely of nationally oriented and of internationally oriented green lobby contributions. Decomposing contributions as in Eq. (8) shows that lobbies with a national focus and those with an international focus create stability effects that work in opposite directions. Whether the stabilising or the destabilising effect dominates, depends on the asymmetry of lobby strength between countries as explained in the previous section.

\section{Conclusions}

We study the influence of political pressure groups both on national emission abatement policies, which includes international spillover effects of national lobbying activities, and on the stability of IEAs. In our model, lobbies announce their contributions before governments choose their participation. The participation decision is followed by the choice of abatement strategies considering both net benefits of abatement and lobby contributions. Finally, lobby contributions are paid contingent on the governments' abatement decisions. We assume that there are two lobbies from which governments obtain contributions: industry and environmentalist. We consider that the levels of the respective contributions depend on each lobby's payoff function and the abatement strategy chosen by the governments. The payoffs of environmentalist lobbies depend on global abatement efforts. Further we assume that the industry lobby is always harmed if the government increases abatement. In Sect. 5 we additionally consider green lobby groups that have an interest in national abatement only.

In our model, lobby contributions affect the abatement decisions of IEA signatories and outsiders. Firms' contributions reduce emission abatement of the host country of the lobby, while environmentalists' contributions give incentives for more ambitious abatement targets. While firms' lobbying activities only influence the abatement levels of the host country, be it a coalition member or a free-rider, we observe a leverage effect of green lobby activities in member countries: a stronger green lobby increases the abatement levels not only of the host country but also of all other members. Clearly the green lobby are environmentalists with global concerns. Their payment incentivises the government to adopt policies that increases global abatement which happens if the government enters an agreement. As a signatory, a government will not only increase domestic abatement, but also indirectly stimulate others to increase abatement, since fellow members account for that country's abatement benefits. If we extend the model 
to have both nationally and internationally oriented green lobbies, we can distinguish the two effects clearly: national green interests incentivise higher abatement efforts in the host countries, whereas internationally oriented green lobbies only have an indirect effect on fellow members.

The effects on coalition stability are less straightforward. Lobbying activities in freeriding countries have no effect on the internal stability of IEAs, whereas lobby groups in countries that are coalition members affect coalition stability. Firms' lobby contributions have a stabilising effect on the coalition if benefits from abatement are evenly distributed among members. If benefits from abatement are sufficiently dispersed among other members, firms' contributions will have a negative impact on coalition stability. The effect of green lobby contributions also depends on the distribution of benefits that governments gain from abatement: if the host country has sufficiently high revenues from abatement, they have a positive effect on coalition stability. However, if the host country has sufficiently low revenues from abatement, green lobby contributions have a destabilising effect. Our results qualify the findings of Marchiori et al. (2017) by allowing for asymmetric countries. In case of symmetric countries, we also find a stabilising effect of firm's lobby contributions on the coalition. However, this effect changes when countries are sufficiently asymmetric in their benefits from abatement in which case increasing firm contributions decrease coalition stability. Considering the differentiated analysis with internationally and nationally motivated green lobby groups we can distinguish two clear-cut effects: increased green lobby strength with a national focus decreases coalition stability, whereas an increase in internationally oriented green lobby strength increases coalition stability. We can conclude that the influence of lobby groups does not only change the abatement decisions of countries but also affects the stability of IEAs. It indeed may have a positive effect on the stability of IEAs, but the effect on coalition stability crucially depends on the composition of the coalition and is often not straightforward.

If we consider the welfare implications of lobby activities, we can distinguish three effects. First, from a global perspective we generally have underprovision of abatement. Hence, when lobby activities increase (decrease) the size of the coalition, underprovision will be reduced (increased) and we would observe efficiency and welfare gains (losses). Second, where green lobby activities increase abatement of a single country or a coalition but do not change the coalition size, green lobbying distorts abatement away from the level that is optimal for the country or coalition. Still, from a global perspective such distortion could reduce underprovision and improve welfare. Third, firms' lobby contributions, if these leave the coalition size unaffected, distort the nationally efficient provision level and increase underprovision of abatement at a global level.

To further explore potential implications of lobbying, consider a transfer mechanism, e.g. via a carbon market where a country with large benefits or a government with strong support from a green lobby can buy the cooperation of others (cf. Fuentes-Albero and Rubio 2010). Via the carbon market, funds will flow from a large-benefits country (permit buyer) to other coalition members with lower benefits but cheap abatement options (permit sellers). Hence, our model results imply that a strong green lobby can have an impact beyond domestic policies and stimulate effective IEAs in a country with high marginal benefits of abatement and in a setting where countries are heterogeneous with respect to marginal benefits. By contrast, green lobby contributions in a country with low marginal benefits will work to the effect that the country would abate more and be less inclined to enter the agreement as a carbon seller. Similarly, a strong industry lobby in a country that is a potential permit seller would impede coalition membership. 
Acknowledgements The authors would like to thank Klaus Eisenack, Bård Harstad, Matthias Kalkuhl, Ulrike Kornek, Carmen Marchiori, Antony Millner, Alessandro Tavoni, Ralph Winkler as well as audiences at the London School of Economics, Humboldt-Universität zu Berlin, the AURÖ Workshop 2016 in Leipzig, the Journées LAGV 2017 in Aix-en-Provence, the CTN Workshop 2017 in Moscow, and the WCERE 2018 in Gothenburg for valuable discussions, comments and suggestions. Moreover, comments by two anonymous reviewers have significantly improved this paper. Financial support from the German Federal Ministry of Education and Research (BMBF) under the research program "Economics of Climate Change" (Grant No. 01LA1811C) is gratefully acknowledged.

Open Access This article is licensed under a Creative Commons Attribution 4.0 International License, which permits use, sharing, adaptation, distribution and reproduction in any medium or format, as long as you give appropriate credit to the original author(s) and the source, provide a link to the Creative Commons licence, and indicate if changes were made. The images or other third party material in this article are included in the article's Creative Commons licence, unless indicated otherwise in a credit line to the material. If material is not included in the article's Creative Commons licence and your intended use is not permitted by statutory regulation or exceeds the permitted use, you will need to obtain permission directly from the copyright holder. To view a copy of this licence, visit http://creativecommons.org/licenses/by/4.0/.

\section{Appendix}

\section{Proof of Proposition 1}

As the abatement decisions are given by (3) for singletons and (5) for IEA-signatories, comparative statics show that (1) firms' lobby activities lower abatement:

$$
\begin{aligned}
& \forall i \in N \backslash S: \frac{\partial q_{i}^{\text {out }}}{\partial \phi_{i}}=-\frac{\lambda_{i}\left(b+\lambda_{i} \gamma_{i}\right)}{c\left(1+\lambda_{i} \phi_{i}\right)^{2}}<0, \\
& \forall i \in S: \frac{\partial q_{i}^{s}}{\partial \phi_{i}}=-\frac{\lambda_{i} \sum_{i \in S}\left(b+\lambda_{i} \gamma_{i}\right)}{c\left(1+\lambda_{i} \phi_{i}\right)^{2}}<0 .
\end{aligned}
$$

(2) Greens' lobby activities increase abatement:

$$
\begin{aligned}
& \forall i \in N \backslash S: \frac{\partial q_{i}^{\text {out }}}{\partial \gamma_{i}}=\frac{\lambda_{i}}{c\left(1+\lambda_{i} \phi_{i}\right)}>0 \\
& \forall i \in S: \frac{\partial q_{i}^{s}}{\partial \gamma_{i}}=\frac{\lambda_{i}}{c\left(1+\lambda_{i} \phi_{i}\right)}>0 .
\end{aligned}
$$

(3) Green lobby activities of signatories have positive spillover effects on other members

$$
\forall i, j \in S, j \neq i: \frac{\partial q_{i}^{s}}{\partial \gamma_{j}}=\frac{\lambda_{j}}{c\left(1+\lambda_{i} \phi_{i}\right)}>0 .
$$

It is also clear that singletons are not affected by any spillovers

$$
\begin{aligned}
& \forall j \neq i: \frac{\partial q_{i}^{\text {out }}}{\partial \phi_{j}}=0, \\
& \forall j \neq i: \frac{\partial q_{i}^{\text {out }}}{\partial \gamma_{j}}=0,
\end{aligned}
$$

and that firms' lobbying in country $i \in S$ does not affect other members 


$$
\forall i, j \in S, j \neq i: \frac{\partial q_{i}^{s}}{\partial \phi_{j}}=0
$$

\section{Proof of Proposition 2}

Rearranging Eq. (2) gives $\pi_{i}=\left(b+\lambda_{i} \gamma_{i}\right) q-\frac{1}{2} c\left(1+\lambda_{i} \phi_{i}\right) q_{i}^{2}+\lambda_{i} \hat{L}_{i}^{f}$.

Now define $\beta_{i} \equiv b+\lambda_{i} \gamma_{i}$ and $\alpha_{i} \equiv c\left(1+\lambda_{i}^{2} \phi_{i}\right)$ in order to write

$$
\pi_{i}=\beta_{i} q-\frac{1}{2} \alpha_{i} q_{i}^{2}+\lambda_{i} \widehat{L}_{i}^{f}
$$

This shows that our game with lobbying can be represented as a linear quadratic public goods game with asymmetric players. Using (A1) and optimal abatement levels (3) and (5) we can rewrite (6), the condition for potential internal stability, as follows: ${ }^{10}$

$$
0 \leq \Phi=-\frac{1}{2}\left(\sum_{i \in S} \beta_{i}\right)^{2} \sum_{i \in S} \frac{1}{\alpha_{i}}-\frac{3}{2} \sum_{i \in S} \frac{\beta_{i}^{2}}{\alpha_{i}}+\sum_{i \in S} \beta_{i} \sum_{i \in S} \frac{\beta_{i}}{\alpha_{i}}+\sum_{i \in S} \beta_{i}^{2} \sum_{i \in S} \frac{1}{\alpha_{i}} .
$$

It is clear from (A2) that coalition stability only depends on parameters $\alpha_{i}$ and $\beta_{i}$ with $i \in S$ and, thus, is independent of lobby activities of non-signatories.

\section{Proof of Proposition 3}

We examine the effect of green lobby activities in a member country on coalition stability by checking the sign of $\frac{\partial \Phi}{\partial \gamma_{i}}$. Notice that $\frac{\partial \beta_{i}}{\partial \gamma_{i}}=\lambda_{i}$ and $\frac{\partial \alpha_{i}}{\partial \gamma_{i}}=0$. Hence we can simply consider $\frac{\partial \Phi}{\partial \beta_{i}}$. Taking derivatives of (A2) we obtain

$$
\begin{aligned}
\frac{\partial \Phi}{\partial \beta_{i}} & =\sum_{j \in S} \frac{1}{\alpha_{j}}\left(2 \beta_{i}-\sum_{j \in S} \beta_{j}\right)+\sum_{j \in S} \frac{\beta_{j}}{\alpha_{j}}+\frac{1}{\alpha_{i}} \sum_{j \in S} \beta_{j}-3 \frac{\beta_{i}}{\alpha_{i}} \\
& =\left(\frac{1}{\alpha_{i}}+\sum_{j \in S_{-i}} \frac{1}{\alpha_{j}}\right)\left(\beta_{i}-\sum_{j \in S_{-i}} \beta_{j}\right)+\sum_{j \in S_{-i}} \frac{\beta_{j}}{\alpha_{j}}+\frac{1}{\alpha_{i}} \sum_{j \in S_{-i}} \beta_{j}-\frac{\beta_{i}}{\alpha_{i}} \\
& =\beta_{i} \sum_{j \in S_{-i}} \frac{1}{\alpha_{j}}-\sum_{j \in S_{-i}} \frac{1}{\alpha_{j}} \sum_{j \in S_{-i}} \beta_{j}+\sum_{j \in S_{-i}} \frac{\beta_{j}}{\alpha_{j}} \\
& =\left(\beta_{i}-\sum_{j \in S_{-i}} \beta_{j}\right) \sum_{j \in S_{-i}} \frac{1}{\alpha_{j}}+\sum_{j \in S_{-i}} \frac{\beta_{j}}{\alpha_{j}} .
\end{aligned}
$$

We can see from the first term that it has a positive sign if $\beta_{i}$ is sufficiently large. This is the case if $\gamma_{i}$ is sufficiently large, given the strengths of the lobby contributions in all other signatory countries. This proves part (i). When $\beta_{i}$ is small, the derivative is negative showing a destabilising effect. This proves part (iii).

${ }^{10}$ Condition (A2) has also been established by Weikard (2009, Eq. 10). 
In order to prove part (ii) we have to determine $\beta_{i}$ such that (A2) holds with equality. Splitting sums to pull out $\beta_{i}$ and rearranging gives

$$
\begin{aligned}
\Phi= & 0=\frac{1}{2} \beta_{i}^{2} \sum_{j \in S_{-i}} \frac{1}{\alpha_{j}}+\beta_{i}\left(\sum_{j \in S_{-i}} \frac{\beta_{j}}{\alpha_{j}}-\sum_{j \in S_{-i}} \frac{1}{\alpha_{j}} \sum_{j \in S_{-i}} \beta_{j}\right) \\
& +\sum_{j \in S} \frac{1}{\alpha_{j}}\left(\sum_{j \in S_{-i}} \beta_{j}^{2}-\frac{1}{2}\left(\sum_{j \in S_{-i}} \beta_{j}\right)^{2}\right. \\
& +\sum_{j \in S_{-i}} \frac{\beta_{j}}{\alpha_{j}} \sum_{j \in S_{-i}} \beta_{j}-\frac{3}{2} \sum_{j \in S_{-i}} \frac{\beta_{j}^{2}}{\alpha_{j}} .
\end{aligned}
$$

It is clear that for sufficiently large $\beta_{i}$ the first term dominates the second such that we can always find $\beta_{i}$ that solves the equation. Such $\beta_{i}$ is the threshold value to stabilise coalition $S$.

\section{Proof of Proposition 4}

We examine the effect of firms' lobby activities in a member country on coalition stability by checking the sign of $\frac{\partial \Phi}{\partial \phi_{i}}$. Notice that $\frac{\partial \Phi}{\partial \phi_{i}}=\frac{\partial \Phi}{\partial \alpha_{i}} \frac{\partial \alpha_{i}}{\partial \phi_{i}}, \frac{\partial \alpha_{i}}{\partial \phi_{i}}=c \lambda_{i}>0$ and $\frac{\partial \beta_{i}}{\partial \phi_{i}}=0$. Hence we can simply consider $\frac{\partial \Phi}{\partial \alpha_{i}}$. Taking derivatives of (A2) we obtain

$$
\begin{aligned}
\frac{\partial \Phi}{\partial \alpha_{i}} & =-\frac{1}{\alpha_{i}^{2}}\left(-\frac{1}{2}\left(\sum_{j \in S} \beta_{j}\right)^{2}+\sum_{j \in S} \beta_{j}^{2}+\beta_{i} \sum_{j \in S} \beta_{j}-\frac{3}{2} \beta_{i}^{2}\right) \\
& =-\frac{1}{\alpha_{i}^{2}}\left(-\frac{1}{2}\left(\beta_{i}+\sum_{j \in S_{-i}} \beta_{j}\right)^{2}+\beta_{i}^{2}+\sum_{j \in S_{-i}} \beta_{j}^{2}+\beta_{i}^{2}+\beta_{i} \sum_{j \in S_{-i}} \beta_{j}-\frac{3}{2} \beta_{i}^{2}\right) \\
& =-\frac{1}{\alpha_{i}^{2}}\left(-\frac{1}{2} \beta_{i}^{2}-\beta_{i} \sum_{j \in S_{-i}} \beta_{j}-\frac{1}{2}\left(\sum_{j \in S_{-i}} \beta_{j}\right)^{2}+\sum_{j \in S_{-i}} \beta_{j}^{2}+\beta_{i}^{2}+\beta_{i} \sum_{j \in S_{-i}} \beta_{j}-\frac{1}{2} \beta_{i}^{2}\right) \\
& =-\frac{1}{\alpha_{i}^{2}}\left(\sum_{j \in S_{-i}} \beta_{j}^{2}-\frac{1}{2}\left(\sum_{j \in S_{-i}} \beta_{j}\right)^{2} .\right.
\end{aligned}
$$

Part (i) follows immediately since the derivative $\frac{\partial \Phi}{\partial \phi_{i}}$ is independent of $\alpha_{j}, j \neq i$. For part (ii), notice that the term in brackets is negative for an even distribution of other member countries' green lobby activities. Hence $\frac{\partial \Phi}{\partial \phi_{i}}>0$ and the impact of firms' lobby contribution on coalition stability is positive. As green lobby activities in other member countries are sufficiently dispersed, the term in brackets will be positive and, hence, $\frac{\partial \Phi}{\partial \phi_{i}}<0$. Then the impact of firms' lobby contribution on coalition stability is negative. 


\section{Proof of Proposition 5}

Differentiating (9) and (11) gives the result

$$
\begin{aligned}
& \frac{\partial q_{i}^{s}}{\partial \gamma_{i}^{D}}=\frac{\partial q_{i}^{\text {out }}}{\partial \gamma_{i}^{D}}=\frac{\partial q^{D}}{\partial \gamma_{i}}=\frac{\lambda_{i}}{\alpha_{i}}, \\
& \frac{\partial q_{i}^{\text {out }}}{\partial \gamma_{i}^{I}}=0, \\
& \frac{\partial q_{i}^{S}}{\partial \gamma_{i}^{I}}=0, \\
& \frac{\partial q_{i}^{S}}{\partial \gamma_{j}^{I}}=\frac{\lambda_{j}}{\alpha_{i}}, \forall j \in S, j \neq i .
\end{aligned}
$$

\section{Proof of Proposition 6}

Part (i): We can rewrite (11) as

$$
q_{i}^{s}=\frac{\sum_{j \in S} \beta_{j}+\lambda_{i} \Delta_{i}}{\alpha_{i}}=\frac{\sum_{j \in S} \beta_{j}}{\alpha_{i}}+\frac{\lambda_{i} \Delta_{i}}{\alpha_{i}}
$$

with $\beta_{i} \equiv b+\lambda_{i} \gamma_{i}^{I}, \alpha_{i} \equiv c\left(1+\lambda_{i} \phi_{i}\right)$ as before, and $\Delta_{i} \equiv \gamma_{i}^{D}-\gamma_{i}^{I}$.

In the same way we can rewrite (9) as

$$
q_{i}^{\text {out }}=\frac{\beta_{i}+\lambda_{i} \Delta_{i}}{\alpha_{i}}=\frac{\beta_{i}}{\alpha_{i}}+\frac{\lambda_{i} \Delta_{i}}{\alpha_{i}} .
$$

We now directly see that

$$
\frac{\partial q}{\partial \Delta_{i}}=\frac{\partial q_{i}^{s}}{\partial \Delta_{i}}=\frac{\partial q_{i}^{\text {out }}}{\partial \Delta_{i}}=\frac{\partial q}{\partial \Delta_{i}}=\frac{\lambda_{i}}{\alpha_{i}} .
$$

Using this notation we can now write potential internal stability as

$$
\begin{aligned}
\Phi(S) \equiv & \sum_{i \in S} \Phi_{i}=\sum_{i \in S}\left(\beta_{i} q^{*}(S)-\frac{1}{2} \alpha_{i}\left(q_{i}^{*}(S)\right)^{2}+\lambda_{i} \Delta_{i} q_{i}^{*}(S)\right) \\
& -\sum_{i \in S}\left(\beta_{i} q^{*}\left(S_{-i}\right)-\frac{1}{2} \alpha_{i}\left(q_{i}^{\text {out }}\right)^{2}+\lambda \Delta_{i} q_{i}^{\text {out }}\right) .
\end{aligned}
$$

Differentiating we get 


$$
\begin{aligned}
\frac{\partial \Phi}{\partial \Delta_{i}} & =\frac{\partial\left(\frac{1}{2} \alpha_{i}\left(q_{i}^{\text {out }}\right)^{2}\right)}{\partial \Delta_{i}}-\frac{\partial\left(\frac{1}{2} \alpha_{i}\left(q_{i}^{S}\right)^{2}\right)}{\partial \Delta_{i}} \\
& =\frac{1}{2} \alpha_{i}\left(\frac{\partial\left(q_{i}^{\text {out }}\right)^{2}}{\partial \Delta_{i}}-\frac{\partial\left(q_{i}^{S}\right)^{2}}{\partial \Delta_{i}}\right)=\lambda_{i}\left(q_{i}^{\text {out }}-q_{i}^{S}\right)<0 .
\end{aligned}
$$

This proves part (i).

Part (ii): Recall from the proof of Proposition 1 that

$$
\begin{aligned}
& \frac{\partial q_{i}^{\text {out }}}{\partial \gamma_{i}^{I}}=0, \\
& \frac{\partial q_{i}^{S}}{\partial \gamma_{i}^{I}}=0, \\
& \frac{\partial q_{i}^{S}}{\partial \gamma_{j}^{I}}=\frac{\lambda_{j}}{\alpha_{i}} \forall j \in S, j \neq i
\end{aligned}
$$

and thus

$$
\frac{\partial q}{\partial \gamma_{i}^{I}}=\sum_{j \in S \backslash i} \frac{\lambda_{i}}{\alpha_{j}} .
$$

We can now write $\Phi$ as

$$
\begin{aligned}
\Phi= & \sum_{i \in S} b q^{*}(S)-\sum_{i \in S} \frac{1}{2} \alpha_{i}\left(q_{i}^{*}(S)\right)^{2}+\sum_{i \in S} \lambda_{i}\left(\gamma_{i}^{I}\left(q^{*}(S)-q_{i}^{*}(S)\right)+\gamma_{i}^{D} q_{i}^{*}(S)\right) \\
& -\sum_{i \in S} b q^{*}\left(S_{-i}\right)+\sum_{i \in S} \frac{1}{2} \alpha_{i}\left(q_{i}^{\text {out }}\right)^{2}-\sum_{i \in S} \lambda_{i}\left(\gamma_{i}^{I}\left(q^{*}\left(S_{-i}\right)-q_{i}^{\text {out }}\right)+\gamma_{i}^{D} q_{i}^{\text {out }}\right) .
\end{aligned}
$$

Again, differentiation gives the result: 


$$
\begin{aligned}
& \frac{\partial \Phi}{\partial \gamma_{i}^{I}}=\sum_{j \in S} b \sum_{k \in S \backslash i} \frac{\lambda_{i}}{\alpha_{k}}-\sum_{j \in S \backslash i}\left(q_{j}^{*}(S)\right) \lambda_{i} \\
& +\sum_{j \in S \backslash i}\left(\lambda_{j}\left(\gamma_{j}^{I}\left(\sum_{k \in S \backslash i} \frac{\lambda_{i}}{\alpha_{k}}-\frac{\lambda_{i}}{\alpha_{j}}\right)+\gamma_{j}^{D} \frac{\lambda_{i}}{\alpha_{j}}\right)\right) \\
& +\lambda_{i}\left(\gamma_{i}^{I}\left(\sum_{k \in S \backslash i} \frac{\lambda_{i}}{\alpha_{k}}\right)+\left(q^{*}(S)-q_{i}^{*}(S)\right)\right) \\
& -\sum_{j \in S \backslash i} b \sum_{k \in S \backslash i, j} \frac{\lambda_{i}}{\alpha_{k}}-\sum_{j \in S \backslash i} \lambda_{j} \gamma_{j}^{I}\left(\sum_{k \in S \backslash i, j} \frac{\lambda_{i}}{\alpha_{k}}\right) \\
& =\underbrace{\sum_{j \in S} b \sum_{k \in S \backslash i} \frac{\lambda_{i}}{\alpha_{k}}-\sum_{j \in S \backslash i} b \sum_{k \in S \backslash i, j} \frac{\lambda_{i}}{\alpha_{k}}}_{+} \\
& \underbrace{-\sum_{j \in S \backslash i}\left(q_{j}^{*}(S)\right) \lambda_{i}+\lambda_{i}\left(\gamma_{i}^{I}\left(\sum_{k \in S \backslash i} \frac{\lambda_{i}}{\alpha_{k}}\right)+\left(q^{*}(S)-q_{i}^{*}(S)\right)\right)}_{+} \\
& \underbrace{\sum_{j \in S \backslash i}\left(\lambda_{j}\left(\gamma_{j}^{I}\left(\sum_{k \in S \backslash i} \frac{\lambda_{i}}{\alpha_{k}}-\frac{\lambda_{i}}{\alpha_{j}}\right)+\gamma_{j}^{D} \frac{\lambda_{i}}{\alpha_{j}}\right)\right)-\sum_{j \in S \backslash i} \lambda_{j} \gamma_{j}^{I}\left(\sum_{k \in S \backslash i, j} \frac{\lambda_{i}}{\alpha_{k}}\right)}_{+}>0 .
\end{aligned}
$$

\section{References}

Aidt, T. S. (1998). Political internalization of economic externalities and environmental policy. Journal of Public Economics, 69(1), 1-16.

Aidt, T. S., \& Hwang, U. (2014). To ban or not to ban: Foreign lobbying and cross-national externalities. Canadian Journal of Economics/Revue canadienne d'économique, 47(1), 272-297.

Altamirano-Cabrera, J.-C., Weikard, H.-P., \& Haffoudhi, H. (2007). Influence of political pressure groups on the stability of international climate agreements. Working paper NCCR Climate Working Paper 2007-03, University of Bern-EPFL-Paul Scherrer Institute, Bern.

Alvarado-Quesada, I., \& Weikard, H.-P. (2017). International environmental agreements for biodiversity conservation: A game-theoretic analysis. International Environmental Agreements: Politics, Law and Economics, 17(5), 731-754.

Anger, N., Asane-Otoo, E., Böhringer, C., \& Oberndorfer, U. (2015). Public interest versus interest groups: A political economy analysis of allowance allocation under the EU emissions trading scheme. International Environmental Agreements: Politics, Law and Economics, 16(5), 621-638.

Asheim, G. B., \& Holtsmark, B. (2009). Renegotiation-proof climate agreements with full participation: Conditions for pareto-efficiency. Environmental and Resource Economics, 43, 519-533.

Barrett, S. (1994). Self-enforcing international environmental agreements. Oxford Economic Papers, 46, 878-894.

Barrett, S. (1997). Toward a theory of international environmental cooperation (Chapter 8) (pp. 239-280). Cambridge: Cambridge University Press.

Batina, R. G., \& Galinato, G. I. (2017). The spillover effects of good governance in a tax competition framework with a negative environmental externality. Environmental and Resource Economics, 67(4), $701-724$. 
Bernheim, B. D., \& Whinston, M. D. (1986). Menu auctions, resource allocation, and economic influence. The Quarterly Journal of Economics, 101(1), 1-31.

Carraro, C., Eyckmans, J., \& Finus, M. (2006). Optimal transfers and participation decisions in international environmental agreements. Review of International Organizations, 1, 379-396.

Carraro, C., \& Siniscalco, D. (1993). Strategies for the international protection of the environment. Journal of Public Economics, 52(3), 309-328.

Chepeliev, M., \& van der Mensbrugghe, C. Y. (2020). Global fossil-fuel subsidy reform and Paris agreement. Energy Economics, 85, 104598.

Conconi, P. (2003). Green lobbies and transboundary pollution in large open economies. Journal of International Economics, 59(2), 399-422.

d'Aspremont, C., Jacquemin, A., Gabszewicz, J., \& Weymark, J. (1983). On the stability of collusive price leadership. Canadian Journal of Economics, 16(1), 17-25.

Eichner, T., \& Pethig, R. (2015). Is trade liberalization conducive to the formation of climate coalitions? International Tax and Public Finance, 22(6), 932-955.

El-Sayed, A., \& Rubio, S. J. (2014). Sharing R\&D investments in cleaner technologies to mitigate climate change. Resource and Energy Economics, 38, 168-180.

Finus, M., \& McGinty, M. (2019). The anti-paradox of cooperation: Diversity may pay!. Journal of Economic Behavior \& Organization, 157, 541-559.

Fredriksson, P. (1997). The political economy of pollution taxes in a small open economy. Journal of Environmental Economics and Management, 33(1), 44-58.

Fredriksson, P., Neumayer, E., Damania, R., \& Gates, S. (2005). Environmentalism, democracy, and pollution control. Journal of Environmental Economics and Management, 49(2), 343-365.

Fredriksson, P., Neumayer, E., \& Ujhelyi, G. (2007). Kyoto protocol cooperation: Does government corruption facilitate environmental lobbying. Public Choice, 133(1), 231-251.

Fuentes-Albero, C., \& Rubio, S. J. (2010). Can the international environmental cooperation be bought? European Journal of Operational Research, 202(1), 255-264.

Grossman, G., \& Helpman, E. (1994). Protection for sale. American Economic Review, 84(4), 833-850.

Grossman, G., \& Helpman, E. (1995). Trade wars and trade talks. Journal of Political Economy, 103(4), $675-708$.

Grossman, G., \& Helpman, E. (1996). Electoral competition and special interest politics. Review of Economic Studies, 63(2), 265-286.

Grossman, G., \& Helpman, E. (2001). Special interest politics. Cambridge, MA: MIT Press.

Gunther, M. (2015). In Washington a handful of corporations lobby against climate change. The Guardian, 24 April 2015. Retrieved January, 2020 from https://www.theguardian.com/sustainable--busin ess/2015/apr/24/washington-climate-change-environmental-defense-fund-ceres-mars-google-starb ucks-epa-clean-power-plan.

Habla, W., \& Winkler, R. (2013). Political influence on non-cooperative international climate policy. Journal of Environmental Economics and Management, 66(2), 219-234.

Haffoudhi, H. (2005). The logic of two-level games with endogenous lobbying: Case of international environmental agreements. Technical Report 54, Cahiers de la Maison des Sciences Economiques, serie jaune, Paris.

Hagen, A., Kähler, L., \& Eisenack, K. (2017). Transnational environmental agreements with heterogeneous actors. In M. Ö. Kayalica, S. Cagatay, \& H. Mihci (Eds.), Economics of international environmental agreements: A critical approach (chapter 4) (pp. 79-96). London: Routledge.

Hagen, A., \& Schneider, J. (2017). Boon or bane? Trade sanctions and the stability of international environmental agreements. Oldenburg Discussion Papers in Economics (V-403-17).

Hillman, A., \& Ursprung, H. (1994). Greens, supergreens, and international trade policy: Environmental concerns and protectionism. In C. Carraro (Ed.), Trade, innovation, environment (chapter 1.3) (pp. 75-108). Dordrecht: Kluwer Academic Publishers.

Hoel, M. (1992). International environment conventions: The case of uniform reductions of emissions. Environmental and Resource Economics, 2(2), 141-159.

Jeppesen, T., \& Andersen, P. (1998). Commitment and fairness in environmental games. In N. Hanley \& H. Folmer (Eds.), Game theory and the environment (pp. 65-83). Cheltenham: Edward Elgar.

Kim, G. (2013). Lobbies competition and bilateral international environmental agreements. The Korean Economic Review, 29, 81-96.

Marchiori, C., Dietz, S., \& Tavoni, A. (2017). Domestic politics and the formation of international environmental agreements. Journal of Environmental Economics and Management, 81(1), 115-131.

Marris, E. (2019). Why young climate activists have captured the world's attention. Nature, 573(7775), $471-472$. 
McEvoy, D. M., \& Stranlund, J. K. (2009). Self-enforcing international environmental agreements with costly monitoring for compliance. Environmental and Resource Economics, 42(4), 491-508.

Nagashima, M., Weikard, H.-P., de Bruin, K. C., \& Dellink, R. (2011). International climate agreements under induced technological change. Metroeconomica, 62(4), 612-634.

Nordhaus, W. (2015). Climate clubs: Overcoming free-riding in international climate policy. American Economic Review, 105(4), 1339-1370.

Schulze, G., \& Ursprung, H. (2001). The political economy of international trade and the environment. International environmental economics: A survey of the issues (pp. 62-83). Oxford: Oxford University Press.

Silva, E. C. (2017). Self-enforcing agreements under unequal nationally determined contributions. International Tax and Public Finance, 24(4), 705-729.

Sovacool, B. K. (2017). Reviewing, reforming, and rethinking global energy subsidies: Towards a political economy research agenda. Ecological Economics, 135, 150-163.

Wangler, L., Altamirano-Cabrera, J.-C., \& Weikard, H.-P. (2013). The political economy of international environmental agreements: A survey. International Environmental Agreements, 13(3), 387-403.

Weikard, H.-P. (2009). Cartel stability under an optimal sharing rule. Manchester School, 77(5), 575-593.

Weikard, H.-P., \& Dellink, R. (2014). Sticks and carrots for the design of international climate agreements with renegotiations. Annals of Operations Research, 220(1), 49-68.

Yu, S., Finus, M., \& Weikard, H.-P. (2017). Compliance and stability of international climate agreements with costly enforcement. In S. Yu (Ed.), The stability and effectiveness of international environmental agreements (chapter 5) (pp. 93-115). Wageningen: Wageningen University.

Publisher's Note Springer Nature remains neutral with regard to jurisdictional claims in published maps and institutional affiliations. 